\title{
Nadir Bir Olgu: Ovaryan Hidatik Kist
}

A Rare Case: Ovarian Hydatid Cyst

\author{
Suat Can ULUKENT ${ }^{1}$, Merve ALDIKAÇTIOĞLU TALMAÇ ${ }^{2}$, Emel CANAZ ${ }^{3}$ \\ Alper ŞAHBAZ ${ }^{1}$, İpek YILDIZ ÖZAYDIN ${ }^{4}$, Özgür AKBAYIR ${ }^{3}$ \\ 1. Kanuni Sultan Süleyman Eğitim ve Araştırma Hastanesi, Genel Cerrahi Kliniği, Küçükçekmece, İstanbul \\ 2. Kanuni Sultan Süleyman Eğitim ve Arş. Hast., Kadın Hastalıkları ve Doğum Kliniği, Küçükçekmece, İstanbul \\ 3. Kanuni Sultan Süleyman Eğitim ve Araştırma Hastanesi, Jinekolojik Onkoloji Kliniği, Küçükçekmece, İstanbul \\ 4. Kanuni Sultan Süleyman Eğitim ve Araştırma Hastanesi, Patoloji Kliniği, Küçükçekmece, İstanbul
}

\section{$\ddot{O Z Z E T}$}

Giriş: Kist hidatik çoğunlukla Echinococcus granulosus ve nadiren de Echinococcus alveolaris'in neden olduğu ülkemizde sık görülen paraziter kistik bir hastalıktır. Tüm organlarda görülebilse de en sik yerleştiği organlar karaciğer ve akciğerdir. Adneksiyal alanda görülen kist hidatik hastaliğı ise oldukça nadirdir.

Olgu: 24 yaşında karın ă̆rısı ve karında şişkinlik şikayeti ile klinigímize bașvuran hasta, yapılan ultrasonografi ve bilgisayarl tomografi tetkikleri neticesinde bilateral müsinöz adneksiyal kitle düsünülerek opere edilmiştir. Frozen inceleme sirasinda hidatik kist olduğu tespit edilip post-operatif dönemde buna yönelik tedavi başlanmıştır.

Sonuç: Türkiye gibi endemik bölgelerde adneksiyal kitlelerin ayırıcı tanısinda hidatik kist de akılda bulundurulmalı ve tanıyı kolaylaştırmak için kistin tipik ultrasonografik bulgularına aşina olunmalıdır. Tedavisinde tüm kitlelerin çıkarılması esastır ve kist içeriğinin saçılmasını önlemek için gerekli tedbirler alınmalıdir.

Anahtar Kelimeler: kist hidatik; adneksiyal kitle; echinococcus granulosus

\section{SUMMARY}

Introduction: Hydatid cyst is a parasitic disease which is endemic in our country, caused frequently by Echinoccus granulosus and rarely by Echinococcus alveolaris. Although can be found in all organs, hydatid cyst develop most commonly in liver and lung. Ovarian hydatid cyst is quite rare.

Case: 24 year-old patient was admitted to our hospital with the complaints of abdominal pain and bloating. Ultrasonography and computed tomography revealed an adnexal mass with the suspicion of a mucinous tumor. Therefore, the patient was operated. Hydatid cyst was the preliminary diagnosis in frozen section examination and albendazole treatment was initiated immediately in the postoperative period.

Conclusion: Hydatid cyst should be kept in mind in differential diagnosis of adnexal masses in the endemic countries such as Turkey. Typical ultrasonografic findings of cysts in order to facilitate the diagnosis should be known. The main treatment is the surgical removal of all the cysts; technical precautions should be taken to prevent the spillage of the cyst contents.

Keywords: cyst; hydatid; adnexa uteri; echinococcus granulosus

\section{Iletişim:}

Sorumlu Yazar: Merve ALDIKAÇTIOĞLU TALMAÇ

Adres: Kanuni Sultan Süleyman Eğitim ve Araştrrma Hastanesi Kadın Hast. ve Doğum Kliniği, Küçükçekmece, İstanbul, Türkiye Tel: +90 (212) 4041500

E-Posta: drmrve@hotmail.com

Makale Geliş: 31.07.2015

Makale Kabul: 11.01.2016

DOI: http://dx.doi.org/10.16948/zktb.71874

\section{GíRiș}

Hidatik kist tüm dünyada görülebilmekte ve olguların \% 95'inde Echinococcosis Granulosus saptanmaktadır (1). Echinococcosis tüm Akdeniz ülkelerinde bölgenin en önemli parazitik hastalığı olarak halk sağlığını ve ulusal ekonomiyi etkileyerek ciddi problemler oluşturur (2). Ôzellikle hayvancılıkla uğraşan yörelerde parazitin yaşam döngüsünü tamamlaması için uygun ortamlar oluşmaktadır. Hem sosyal koşulları hem de içinde bulunduğu coğrafya dolayısıyla ülkemiz hastalığın sık görüldüğü yerler arasindadir (3).

Besin olarak tükettiğimiz hayvanlar parazitin ara konağıdır. Son konak olan köpek ise hem çiftliklerde, hem de göçebe ve sürü sahibi toplumlarda bulunur. Köpek insanlara enfeksiyonu taşıyan en önemli kaynaklardan birisidir. Çakal, sırtlan, kurt, tilki gibi vahşi hayvanlarda bulaşma zincirinde rol oynarlar. Kist içeren çiğ etin yenilmesi insanda enfeksiyon oluşturmaz. Ana konağın dışkısı ile kontamine yiyecek ve içeceklerin tüketilmesi ile bulaşır (4). Hidatik kist tüm organları tutabilmekle birlikte en s1k karaciğer $(\% 70)$ ve akciğeri (\% 15-20) tutar. Dalak tutulumu \% 0,9-\% 8 siklıkla bildirilirken, izole dalak tutulumu çok nadirdir. Nadiren yumuşak dokular, kas-iskelet sistemi, kalp ve mesane gibi bölgelerde de görülebilir (5). Parazit genellikle hematojen veya ince barsak lenfatikleri yoluyla yayılır; ancak batın içi yayılımı primer kistin spontan rüptürü ve parazitin intraperitoneal sıvı ile dolaşarak diğer organlara ekilmesi yoluyla da gerçekleşebilir (6). Biz de oldukça nadir yerleşim yerlerinden biri olan adneksiyal alanda kist hidatik saptanan olgumuzu sunmayı amaçladık

\section{OLGU}

Yirmi dört yaşında gravida 1, paritesi 1 olan hasta kliniğgimize karın ağrısı ve karında şişkinlik şikayeti ile başvurdu. Tibbi özgeçmişinde bilinen hastalık veya ilaç kullanımı öyküsü 
olmayan hastanın muayenesinde, batında distansiyona yol açan ve ksifoide kadar uzanan çevre dokulara fikse olduğu izlenimini yaratan kitle palpe edilmiştir. Yapılan ultrasonografide sağ adneksiyal alanda 8-9 cm çapta yoğun içerikli kist, sol adneksiyal alanda ise over kaynaklı olduğu düşünülen $25 \mathrm{~cm}$ çapta, müsinöz kist karakterinde multiseptalı, bal peteği tarzında görünümü olan kistik kitle izlenmiştir (Resim 1,2). Uterus normal olarak değerlendirilmiștir. İstenen tümor marker düzeylerinden CA 125 düzeyi hafif yükselmiș olarak bulunan (CA 125: $65 \mathrm{U} / \mathrm{mL}$; Ca19.9: $9 \mathrm{U} / \mathrm{mL}$; CEA: 0,2 $\mathrm{ng} / \mathrm{mL}$ ) hastaya tüm batın kontrastlı bilgisayarlı tomografi (BT) çekilmiştir.

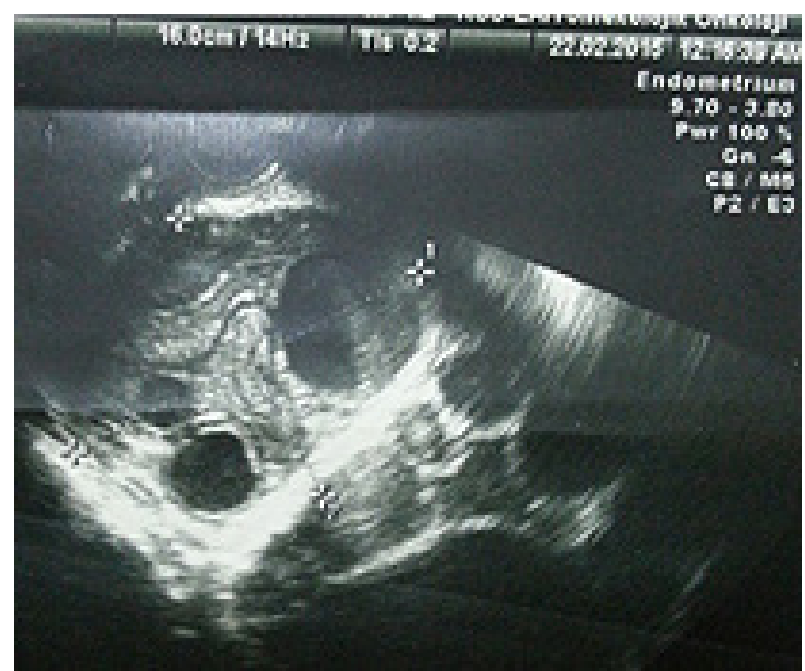

Resim 1: Sağ adneksiyal kitlenin tvusg görüntüsü. Kist içeriğinin yoğunluğu dikkat çekicidir.

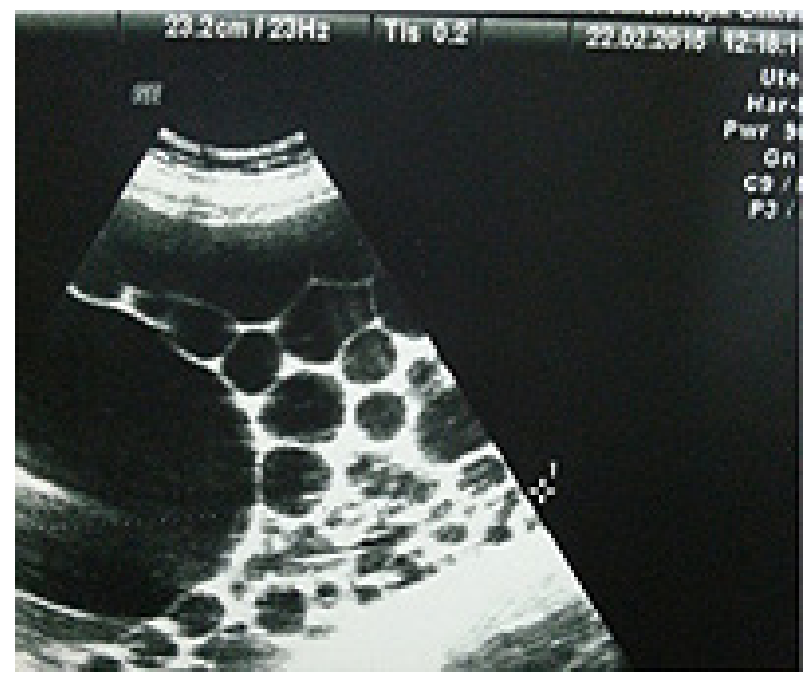

Resim 2: Sol adneksiyal alandan kaynaklandığı düşünülen kitlenin tvusg görüntüsü. Kist içerisinde uniform multiple anekoik kistik boşluklar karakterize bal peteği görünümü izlenmiştir.

Batın BT'de uterus ve sol over doğal olarak izlenmiş; sağ overde septalar gösteren hipodens kistik kitle izlendiği belirtilmiştir. Batında orjini hakkında yorum yapılamayan iç organlara kompresyon yapan muntazam konturlu hipodens kistik yapı izlenmiș olup diğer batın organlarında patoloji görülmemiștir. Karaciğerde kitle imajı izlenmemiştir. Akciğer grafisinde yer kaplayan oluşum veya sıvı izlenmeyen hasta klinik kanaate göre bilateral olduğu düşünülen ovaryan müsinöz tümör ön tanısıyla laparotomi ve frozen amaciyla interne edilmiştir. Hasta bulgularımız 1şığında bilgilendirilerek operasyon kararı için sözel ve yazılı onamı alınmıştır. Göbek altı-üstü median insizyon ile batına girilmiştir. Gözlemde solda dalak hilusuna tutunmuş tüm batını dolduran, içerisinde bal peteği tarzında septaları olan yüzeyi düzgün, yaklaşık $25 \mathrm{~cm}$ çapında kistik kitle; sağda adneksiyal alanda yaklaşık $10 \mathrm{~cm}$ çapında kistik kitle izlenmiștir (Resim 3, 4). Sol over normal yapıda izlenmiștir. $25 \mathrm{~cm}$ çaplı kitlenin preoperatif dönemdeki klinik kanaatin aksine, sol over ile bağlantılı olmadığ 1 ve dalak hilusuna dens olarak bitişik olduğu görülmüştür. Kitlenin dalak orijinli olduğu ve büyüklügü sebebiyle adneksiyal alana superpoze olarak sol adneksiyal kitle görünümü yarattığı görülmüștür. Sağ adneksiyal alandaki $10 \mathrm{~cm}$ büyüklükteki kitlenin ise esas olarak ovaryan kaynaklı olduğu görülmüștür.

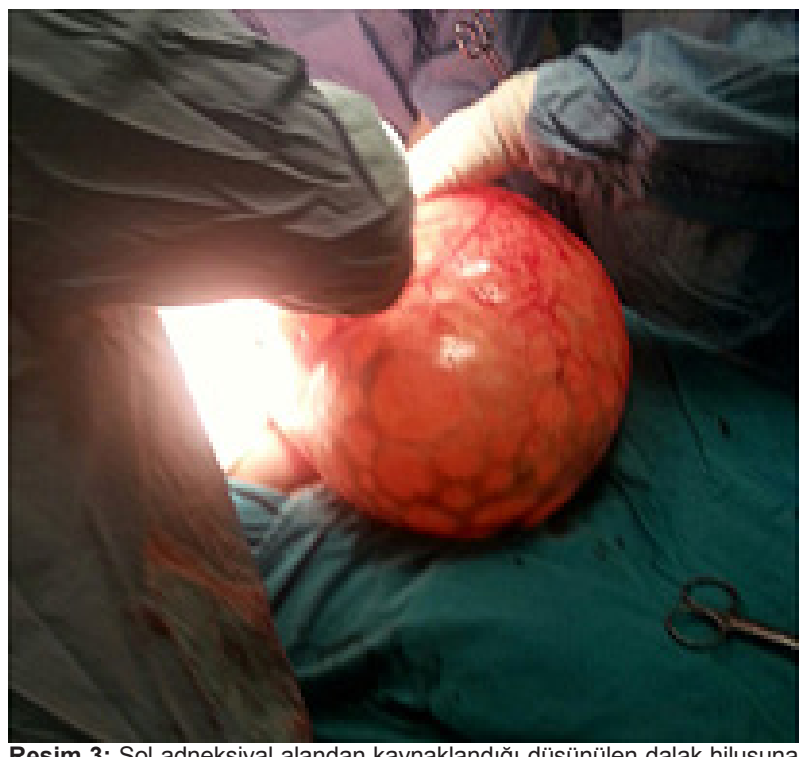

Resim 3: Sol adneksiyal alandan kaynaklandığı düşünülen dalak hilusuna tutunmuş kistik kitle.

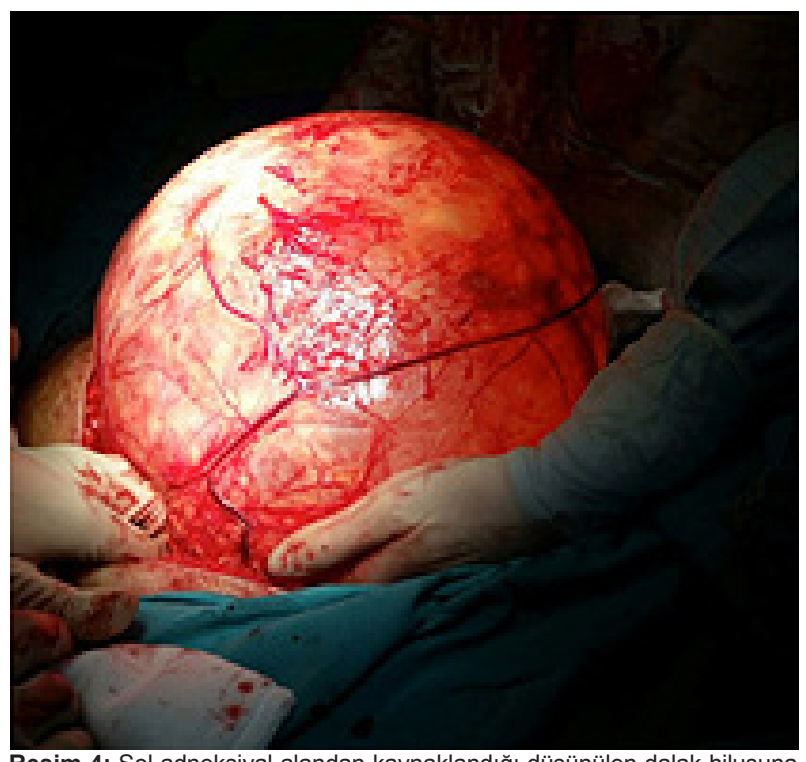

Resim 4: Sol adneksiyal alandan kaynaklandığı düşünülen dalak hilusuna tutunmuş kistik kitle. 


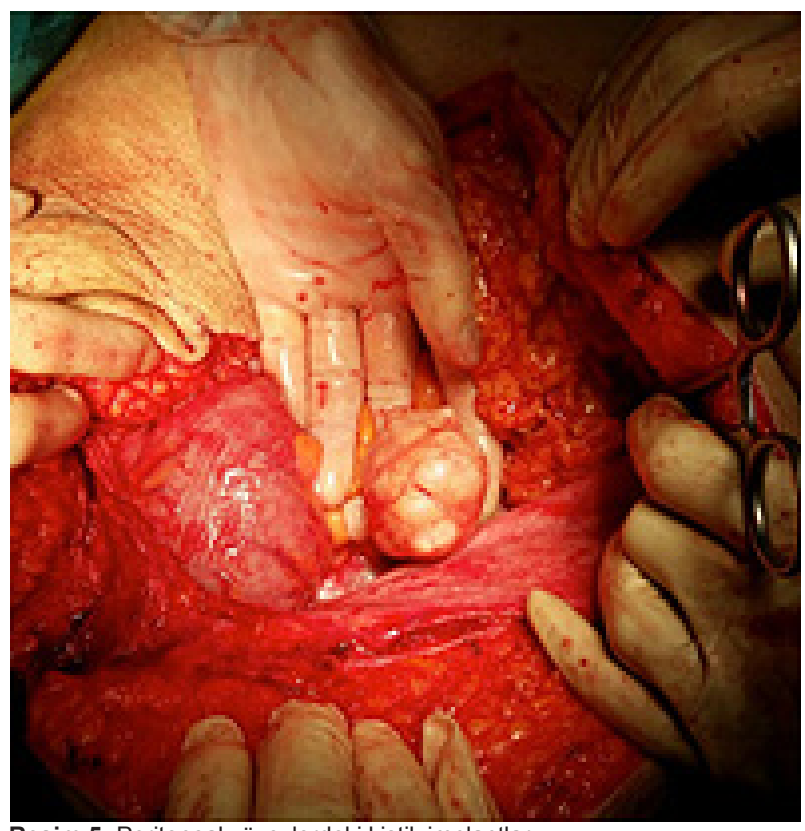

Resim 5: Peritoneal yüzeylerdeki kistik implantlar.

Batını dolduran kitle etrafındaki yapıșıkliklardan diseke edilip dalak hilusuna kadar takip edilmiş ve hiler lojda da tutunduğu alanda rezidüel doku bırakılmayacak şekilde disseke edilerek frozen amaciyla patolojiye gönderilmiştir. Dalak lojundaki diseksiyon esnasında kistin küçük bir alandan rüptüre olduğu ve içinden büyüklükleri $2-5 \mathrm{~cm}$ arasında değișen veziküller boşaldığı görülmüştür. Ayrıca, batın içerisinde peritoneal yüzeylerde ve omentum üzerinde, 3 adet daha etrafindan kolayca disseke olarak ayrılan implantlar izlenmiştir (Resim 5). Sol adneksiyal kitle de sol salpingoooferektomi yapılarak frozen incelemesi için patolojiye gönderilmiştir. Frozen inceleme sonucunda, her iki kistin de kist hidatik ile uyumlu olduğu söylenmiștir. Detaylı eksplorasyonla batın implantlar çıkarılarak batın içerisi Povidone-iodine solüsyonuyla en az 10 dakika yıkanmıştır. Karaciğer ve dalakta ayrıca kitle formasyonu palpe edilmemiştir. Hastaya postoperatif 1.günde $15 \mathrm{mg} / \mathrm{kg} / \mathrm{gün}$ dozunda albendazol tedavisi başlanmıştır. Kesin patoloji sonucunda ekinokokal kist olarak raporlanmıştır (Resim 6-7). Hastadan istenen kist hidatik indirekt hemaglütinasyon testi 1/2560 olarak sonuçlanmıştır. Hastamız postoperatif 7 . gününde komplikasyon olmadan, $15 \mathrm{mg} / \mathrm{kg} /$ gün albendazol tedavisi reçete edilerek taburcu edilmiştir.

\section{TARTIŞMA}

Adneksiyal kitlelerin ayırıcı tanıları arasinda jinekolojik ve non-jinekolojik sebepler bulunmaktadır. Non-jinekolojik sebepler arasinda gastrointestinal ve üriner sisteme ait patolojilerin yanında nadir retroperitoneal kitleler de yeralmaktadır. Hidatik kistler de yerleşimine göre adneksiyal kitleler ile karıştırılabilir, kit- lenin büyüklüğü sebebiyle orijin yeri net olarak görüntülenemeyerek adneksiyal kitle olarak yorumlanabilir. Bunun yanında hidatik kist over üzerine de implante olabilir ki bu durum, kist hidatiğin endemik olduğu bölgelerde bile oldukça nadir bir durumdur (7). Dolayısıyla pre-operatif dönemde tanı alması da bir o kadar güçtür. Bizim olgumuzda da olduğu gibi hasta intra-operatif tanı almış pre-operatif incelemelerde müsinöz tümörle karıșmıștır. Ultrasonografi tanıda en faydalı ve en yaygın olarak kullanılabilecek tanı aracidır. Genellikle soliter, kismen kalsifiye ve anekoik kistler saptanır. Çift duvarlı kistik bir lezyonun içerisindeki hidatik kum tanı koydurucudur. Sunduğumuz olguda olduğu gibi ultrasonografide düzgün yüzeyli kistik kitle içerisinde çok sayıda uniform veziküler görüntünün izlenmesi, adneksiyal kitlenin ayırıcı tanısında hidatik kist yönünden şüphe uyandırmalıdır. Olguların \% 16-30'unda ek olarak karaciğer ve periton tutulumu da görülmektedir. Literatüre göre \%10-40 olguda birden fazla kist saptandığ belirtilmektedir (8). Bizim olgumuzda da peritoneal yaklaşık $4 \mathrm{~cm}$ çapta 3 adet tutulum izlenmişti.

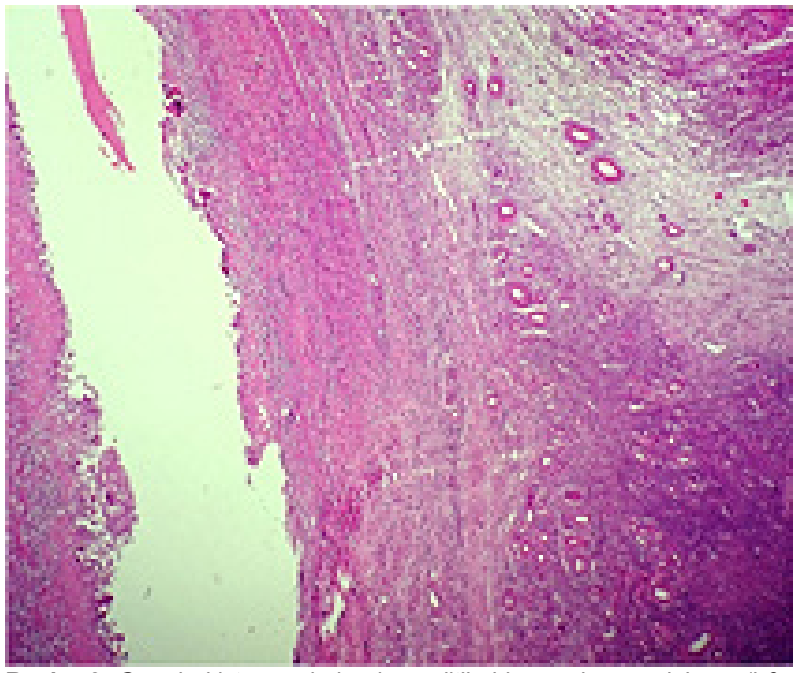

Resim 6: Overde kist çeperinde oluşan iltihabi granülasyon dokusu (h\&e 40x).

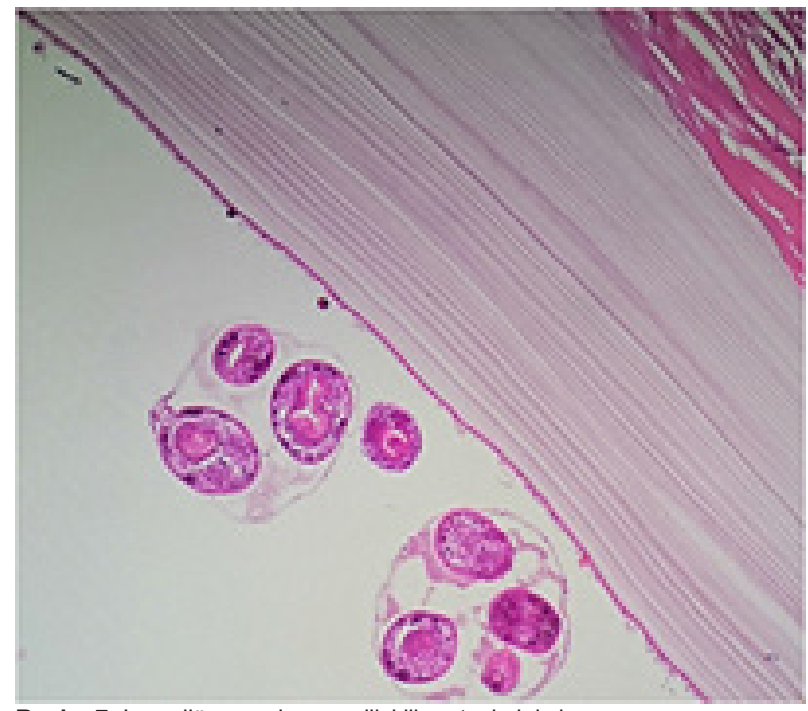

Resim 7: Lamellöz membran ve ilişkili protoskoleksler. 
Tomografi, kist duvarındaki kalsifikasyonları tespit etmesi bakımından direkt grafi ve ultrasonografiden daha üstündür. Tomografide ayrıca karındaki diğer kistlerin gerçek sayı ve yerleşimi hakkında bilgi edinilir. Tomografi ovaryan kitlelerde rekürrensi değerlendirmede $\% 36$ yanlış pozitiflik oranına ve \% 40-60 sensitiviteye sahiptir (9). Manyetik rezonans (MR) kalsifikasyonları saptamak için çok uygun bir görüntüleme yöntemi değildir (10). Ancak tedaviye cevabı değerlendirmek için kullanılabilir. Patolojik incelemede içte germinatif membran (intima) ve dișta lamine membran (kutikula) saptanır. En dişta ise ince fibrotik ve komprese olmuş dalaktan oluşan perikist (adventisya) bulunur (11). Hastaların \%45'inde fizik muayeneleri normaldir. En sik saptanan bulgular hepatomegali ve karında kitledir. Yayınlanmış hemen tüm çalıșmalarda da benzer veriler elde edilmiștir (12). Olgumuzdaki hasta da karında şişkinlik şikayeti ile tarafımıza başvurmuştur. Kist hidatiğin tedavisi için kabul edilen en geçerli yöntem cerrahidir.

Cerrahide amaç tüm paraziter elemanların çıkarılmasıdır (13). Kistin çıkarılması esnasında peritoneal kavite ve yara kenarlarının kist içeriği ile kontaminasyonunu önlemek çok önemlidir. Çünkü kist içeriği çok sayida protoskoleks içermektedir ve bunların her biri ayrı bir hidatik kist oluşturma potansiyeline sahiptir. Ayrica spontan perforasyon sonrasinda anafilaktik reaksiyonların olabileceği de akılda tutulmalıdır. $\mathrm{Bu}$ nedenle kist içine skolisidal ajanların verilmesi, operasyon sırasında kistin rüptüre edilmemesi için özen gösterilmesi ve skolisid emdirilmiş kompreslerle kontanimasyonun minimalize edilmesi alınabilecek önlemlerdir (14). Kullanılabilecek skolisidal ajanlar arasinda formalin, hipertonik salin, cetrimide, klorheksidin, hidrojen peroksid, polivinilpirrolidon-iodin ve etil alkol bulunur; ancak bu ajanların her birinin potansiyel toksisitesi vardır ve hangi ajanın hangi konsantrasyonda ve ne kadar süre kullanılacağı ile ilgili bir fikir birliği yoktur. Örnegin, etil alkol ve \%20 hipertonik salin ile irrigasyonların efektif skolosidal etkileri olduğu gösterilmişse de ciddi hepatobiliar komplikasyonlar bildirilmiştir (15). Hidrojen peroksit ile yapılan irrigasyonlarda ise anaflaktik şok ve hava embolisi bildirilmiştir (16). Cetrimide efektif bir ajan olsa da metabolik asidoz ve methemoglobinemi gibi yan etkileri vardır. Bununla birlikte, Püryan ve arkadaşlarının yaptıkları deneysel çalışmada \%0.04'lük klorheksidin glukonat en potent non-toksik ajan olarak gösterilmiştir (17). Ekçi ve arkadaşları da yaptıkları deneysel çalışmalarında \%1'lik polivinilprolidon-iyot ile 5 dakika irrigasyonun oldukça etkin bir metod olduğunu göstermişler- dir (18). Medikal tedavi postoperatif dönemde rekürrensin önlenmesinde etkilidir. Preoperatif dönemde başlanan ve postoperatif devam edilen $12-15 \mathrm{mg} / \mathrm{kg} / \mathrm{gün}$ albendazol tedavisine ek olarak cerrahi sırasında kistik kavitenin albendazol ile yapilan irrigasyonu ile rekürrens oranının \%14.3'ten \%1'e kadar düşürüldüğü gösterilmiştir (19). Albendazol tedavisi sırasında nötropeni ve karaciğer tansaminazlarında yükselme olabileceğinden hematoloji ve biyokimya testleri ile kontrol edilmelidir. Tranaminazların yüksekliği veya nötropeni tedavinin kesilmesini gerektirebilir. Postoperatif dönemde hastalar serolojik testler ve postoperatif ilk hafta içinde, 1., 6. ve 12. aylarda ultrasonografi veya bilgisayarlı tomografi ile rekürren veya sekonder hastalık açısından izlenmelidir. Tedavinin postoperatif 2 ay veya daha fazla devam etmesi önerilir (20).

\section{SONUÇ}

Sonuç olarak; adneksiyal alandaki kitlelerin ayırıc1 tanısinda nadir sebeplerden biri olarak hidatik kist de akılda bulundurulmalıdır. Bunun hem direkt implantasyon sonucu gelişmiş ovaryan orjinli bir kitle olabileceği, hem de batın içindeki başka bir kitlenin büyüklük ve yerleşimi nedeniyle adneksiyal kitle görünümü yaratabileceği bilinmelidir. Kistin tipik ultrasonografik bulgularına aşina olunması ayırıcı tanıyı kolaylaştırır. Şüphelenilen olgularda ekinococcus hemaglütinasyon testi istenebilir. Tedavisinde tüm kitlelerin çıkarılması ve kontaminasyonun minimalize edilmesi esastır ancak kist hidatiğin endemik olduğu bölgelerde hastalıkla mücadelenin esas olarak korunma ve kontrol yöntemleriyle başarılabileceği unutulmamalıdir.

\section{$K A Y N A K L A R$}

1. Safioleas M, Misiakos E, Manti C. Surgical treatment for splenic hydatidosis. World J Surg 1997;21(4):374-377.

2. Munzer D. New perspectives in thediagno- sis of Echinococcusdisease. J ClinGastroenterol 1991;13:415-23.

3. Barış I, Şahin A, Bilir N, editors. Kist hidatidhastalı̆̆l ve Türkiye'deki konumu. Ankara: TürkiyeAkciğer Hastalıkları Vakfi; 1990.

4. Tünger Ö. Epidemiology of cystic echinococcosis in the world. TürkiyeParazitol Derg.2013; 37(1):47-52. doi:10,5152/tpd.2013.12.

5. Durgun V, Kapan S, KapanM,etal.Primary splenic hydatidosis. Dig Surg 2003;20(1):38-41.

6. Mourglia-Ettlin G, Marqus JM, Chabalgoity JA, Dematteis $S$. Early peritoneal immune response during Echinococcus granulosus establishment displays a biphasic behavior. PLoS Negl Trop Dis. 2011;5:e1293. 
7. Gamoudi A et al. Ovarian hydaticcyst. 7 cases. J GynecolObstetBiolReprod (Paris). 1995; 24 (2); 144-8.

8. Von Sinner WN, Stridbeck H. Hydatid disease of the spleen. Ultrasonography, CT and MR imaging.ActaRadiol. $1992 \mathrm{Sep} ; 33(5): 459-461$.

9. Kubik-Huch RA, Dorffler W, von Schulthess GK, et al. Value of 18-FDG PET, CT and magnetic resonance imaging in diagnosis primary and recurrent ovarian carcinoma. Eur Radiol 2000; 10(5):761-7.

10. Marani SA, Canossi GC, Nicoli FA, Alberti GP, Monni $S G$, Casolo PMHydatid disease: MR imaging study. Radiology 1990. Jun;175(3):701-6

11. Pedrosa I, Saiz A, Arrazola J, et al. Hydatid disease: radiologic and pathologic features and complications. Radiographic 2000;20(3):795-817

12. Safioleas M, Misiakos E, Manti C, Katsikas D, Skalkeas G. Diagnosticevaluationandsurgicalman-agement of hydatiddisease of the liver. World J Surg 1994; 18:859-65.

13. Chrieki M. Echinococcosis-an emerging parasite in the immigrant population. Am Fam Physician 2002;66:817-20.

14. Tozar E, Topcu O, Karayalcin K, Akbay SI, Hengirmen $S$. The effects of cetrimide-chlorhexidine combination on the hepatopancreatico-biliary system. World J Surg 2005, 29:754-758
15. Yetim I, Erzurumlu K, Hokelek M, Baris S, Dervisoglu A, Polat C, Belet U, Buyukkarabacak Y, Guvenli A. Results of alcohol and albendazole injections in hepatic hydatosis: experimental study. J Gastroenterol Hepatol 2005, 20:1442-1447.

16. Adas G, Arikan S, Kemik O, Oner A, Sahip N, Karatepe $O$. Use of albendazole sulfoxide, albendazole sulfone, and combined solutions as scolicidal agents on hydatid cysts (in vitro study). W J Gastroenterol 2009, 15:112-116.

17. Puryan K, Karadayi K, Topcu O (2005) Chlorhexidine gluconate: an ideal scolicidal agent in the treatment of intraperitoneal hydatidosis. World J Surg 29:227-230.

18. Ekçı B, Gürol Y, Aydin I, Yalniz F, Ozcan M, Zengın K. [The protoskolicidal effect of $1 \%$ polyvinylpyrrolidone-iodine $(P V P-1)$ and $2 \%$ taurolidine on abdominal hydatidosis. Turkiye Parazitol Derg. 2010;34(3):152-5.

19. Karabulut K., Ozbalci G.S., Kesicioglu T., Tarim I.A., Lap G., Polat A..K., Karabicak I., Erzurumlu K. Long-term outcomes of intraoperative and perioperative albendazole treatment in hepatic hydatidosis: single center experience. Annals of Surgical Treatment and Research 2014;87(2):6165 .

20. Polat C, Dervisoglu A, Hokelek M, Yetim I, Buyukkarabacak Y, Ozkutuk Y, et al. Dual treatment of albendazole in hepatic hydatidosis: new therapeutic modality in 52 cases. J Gastroenterol Hepatol 2005; 20:421-5. 